\title{
O meu corpo em perceção: uma relação com a câmara e com o ato de ser fotografada
}

\author{
Cristianne de Sá \\ Universidade de Aveiro - DeCA, Portugal \\ Paulo Bernardino Bastos \\ Universidade de Aveiro - DeCA, Portugal \\ ID+ Instituto de Investigação em Design Media e Cultura, Portugal
}

\begin{abstract}
What is purposed in the article is the thinking of the body in perception from a single experience or from the body and its relationship with the camera and with the act of being photographed or portrayed. Thinking that the camera can be an expanded body and also referring to the photographer and his/her act not only with the shoot but loaded with all the circumstances that embrace the space. Here who proposes a thought around this relationship is not even the author, but the character explaining a revealing and impulsive experience about the creation of the movement and the statics, consciously. From this experience - The confrontation between the character and the author taking the character to impose its ideas and work with the image, photographer, camera and body as his/her leitmotiv throughout the authorial work.
\end{abstract}

Keywords: Perception, Body, Image, Experience, Camera

\section{Introdução}

O corpo humano não pode ser considerado apenas como um objeto lançado no espaço contextual, ele interage, interferindo e sendo contagiado pelo contexto. O corpo desde a sua pré-história vem se modificando e se transformando, estão ligados à vários aspectos sejam estes físicos, sociais ou culturais. Sua representação perpassa pelos valores éticos e morais que são determinados por grupos sociais que tiveram e ainda tem papel fundamental como a família e a religião. No corpo temos inscritas todas as regras, as normas e valores de cada sociedade em particular "por ser ele o meio de contacto primário do indivíduo com o ambiente que o cerca" (Daolio 1995, 105).

Entretanto, é importante acentuarmos, como diz o prórprio autor Daolio, que todos estes aspectos sociais, são de extrema influência em nossos corpos, mas que são primárias, ou seja, os corpos também são capazes de serem alterados pela perceção própria do percursso ao longo da sua experiência, são alterações e transformações singulares, que não provém de antecedentes ou do ambiente físico e social mas caminham segundo o teórico Merleau-Ponty em seu livro Fenomenologia da Perceção $(1999,4)$ em direção a eles e os sustenta, pois somos nós quem damos os signficados para nós mesmos, somos nós que nos defenimos e nos colocamos diante o mundo.
As representações científicas segundo as quais eu sou um momento do mundo são sempre ingênuas e hipócritas, porque elas subentendem, sem mencioná-la, essa outra visão, aquela da consciência, pela qual antes de tudo um mundo se dispõe em torno de mim e come-ça a existir para mim. (Merleau-Ponty 1999, 4)

O que proponho neste artigo é pensar o corpo em perceção a partir de uma experiência própria ou do corpo próprio ${ }^{1}$ a relação com a câmara e com o ato de ser fotografada. Pensando esta câmara como um corpo expandido referindo-se também ao fotógrafo e este ato não simplesmente como o disparo, mas, carregado de todas as circunstâncias que envolvem este espaço.

A foto não é apenas uma imagem (o produto de uma técnica e de uma ação, uma figura de papel em sua clausura de objeto finito), é também um ato icônico, uma imagem, se quisermos, mas em trabalho, algo que não é possível conceber fora de suas circunstâncias. A foto é uma imagem-ato que não se limita apenas ao gesto da produção (o gesto da tomada), mas que inclui o ato de sua recepção e sua contemplação. (Dubois 1999, 15).

Aqui quem propõe um pensamento acerca desta relação não é o autor, mas a personagem. Para isso coloco-me como sujeito deste artigo e opto também por uma escrita em $1^{\circ}$ pessoa pois é a partir das minhas memórias e experiências que reflito o que seria este corpo em perceção e o que ele é capaz de articular quando tomado pelos movimentos de vivências que o cercam. A partir desta perspetiva, vimos como necessário fazer uma introdução acerca do contexto em que vivia quando a experiência de perceção deste meu corpo começou a tomar proporções que delinearam totalmente o meu corpo hoje e que me levaram à descoberta do trabalho artístico autoral.

Em 2003, eu, Cristianne de Sá, era uma estudante de Jornalismo no Brasil, em Minas Gerais, tinha 23 anos e tive a oportunidade de ter uma graduação pautada por uma visão experimental através do Novo Jornalismo ou Jornalismo Literário. O Novo Jornalismo é uma corrente que surgiu nos anos 60 nos Estados Unidos através de um grupo de jornalistas que estavam incomodados com a vida em um modo geral, pois os Estados Unidos viviam uma grande efervescência cultural e começaram, assim, a achar que deveria ter uma outra forma de se fazer jornalismo que não fosse somente esse legitimado pelo jornalismo tradicional. A objetividade presente nos textos deste jornalismo tradicional foi substituída 
através deste grupo de jornalistas por uma escrita mais literária, eles começaram a contar histórias do cotidiano, histórias que eram notícias que estavam ali, estavam acontecendo mesmo no dia-a-dia ${ }^{2}$.

A partir deste contexto no qual estava inserida, onde o ato de olhar envolta e olhar o outro e se olhar se fez bastante presente e delicado, eu já carregava comigo também as experiências das aulas de teatro que iniciei aos 14 anos. Eu tinha muito desejo pelo teatro, mas, ainda não havia iniciado meu trabalho enquanto uma atriz profissional e aquele espaço universitário era o lugar onde eu podia experimentar uma forma de se fazer jornalismo que não excluiria o corpo, a criação artística e a experiência com a imagem, mas esta, de uma forma outra, menos ácida e invasiva como os jornais tradicionais costumavam fazer. Eu poderia, assim, experimentar fazer teatro e escrita literária como uma outra forma de contar uma história, que poderia também, ser jornalística.

No percurso desta graduação conheci um fotógrafo, que irei aqui, nomeá-lo de $X^{3}$. Ele tinha 25 anos e já visionava ser um artista visual. Eu e $X$ começamos a trocar experiências através dos nossos encontros, que duraram aproximadamente 5 anos.

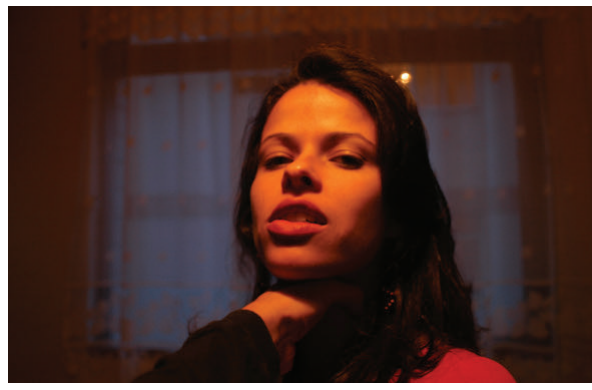

Figura 1 - Cristianne de Sá e X, 2003.

A vivência se dava com o ato fotográfico. Ele me fotografava, pedia para eu me colocar em um determinado lugar ou movimentar meu corpo a partir de suas coordenadas, e em outros momentos, eu mesma propunha. Algumas vezes eu era fotografada mesmo quando ele acreditava que eu estava dormindo, mas ao contrário, eu estava ali de olhos fechados, imóvel, em estado de perceção e ouvindo o disparo da câmara. Algumas ocasiões ele me fotografava sentada em algum sofá ou na janela a olhar. Muitas vezes nua e outras tantas com roupa, gestos naturais, genuínos ou encenados. Mas uma coisa parecia clara para mim e para ele: eu não era uma modelo! Eu não estava ali com o intuito de ser fotografada, eu estava vivendo aquele encontro.

Depois de muito tempo, em torno de 4 anos que se iniciaram estes encontros ele pediu também para eu lhe fotografar. A minha presença em sua casa se dava com a presença da sua câmara. Ele estava ali, a câmara esta ali, o espaço esta ali, e eu, olhava para esta câmara, olhava para ele e as vezes desviava o olhar, mas em todos estes momentos, apesar de um extremo silêncio da minha parte eu buscava perceber e olhar em volta. Se instaurou mesmo uma atmosfera que eu nunca havia vivido e se instaurava no corpo, eu sentia que algo de grandioso estava a acontecer e poucas vezes ou raramente pedia para ver qualquer fotografia quando esta tinha acabado de ser feita. Eu realmente não me preocupava em ver estas imagens, eu não queria, e acreditava que ao fazer isso poderia perder o fluxo daquilo que se passava ali.

Isso resultou-se em vários questionamentos que envolvia o corpo, o espaço a fotografia e o lugar do personagem e autor. Criou-se então uma grande relação com a câmara e com o ato de ser fotografada, com o espaço, com o tempo, com a imagem, com meu corpo e com o próprio fotógrafo. A medida que os anos foram se passando eu fui me transformando e acredito que ele também, não sei exatamente quando, mas sei que algo se revelou também para ele.

No andar desta experiência, me graduei em Jornalismo e entrei para um grupo de teatro profissional: Boca de Cena e permaneci neste grupo de teatro por cerca de 9 anos. Em 2006 fui estudar história da arte em uma especialização e em 2007, aos 27 anos, surgiu então o grande confronto entre eu e X: eu não era apenas uma personagem! Resultando, assim, em um grande rompimento entre eu e ele. $\mathrm{O}$ ato de ter sido fotografada por alguns anos criou em mim uma potência que tirou tudo do lugar. Foi preciso então, juntar os eixos, mesmo que estes nunca mais sejam os mesmos, como se isso fosse fonte de continuação. O corpo estava agora outro e era preciso entender isso.

Em 2009 convidei outros 4 fotógrafos para dar continuidade: me fotografarem! Já que a relação com $X$ havia se rompido e eu sentia uma forte necessidade de continuar sendo fotografada. Mas algo mudara, desta vez, a autoria daquelas ações eram nítidas, uma parceria entre eu e eles ou uma dupla.

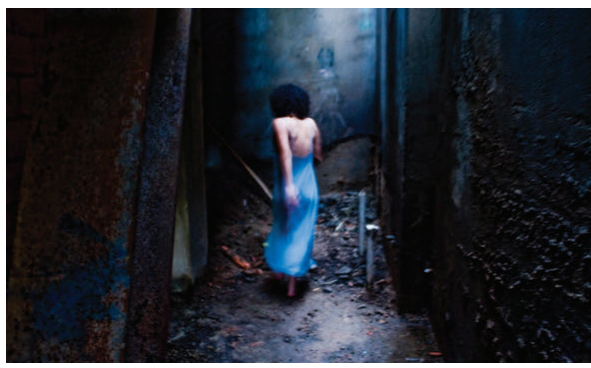

Figura 2- Cristianne de Sá e Pedro David, 2008. 


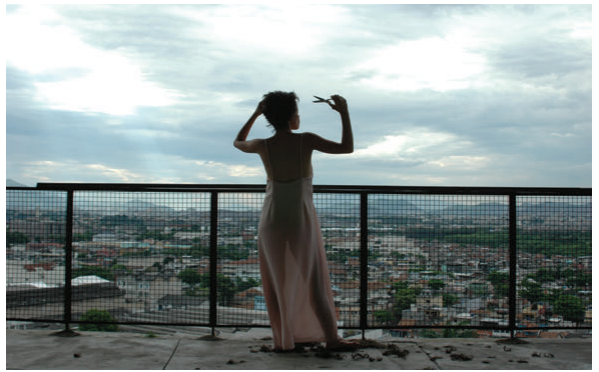

Figura 3 - Cristianne de Sá e Paula Huven, 2009.

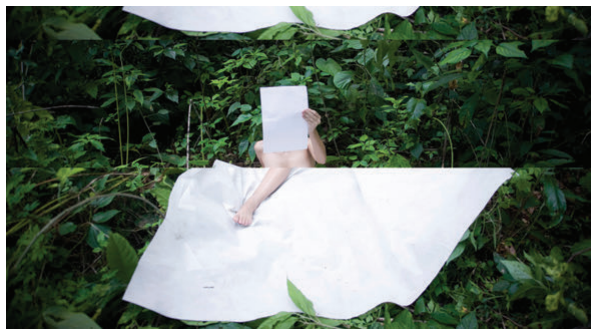

Figura 4 - Cristianne de Sá e anônimo, 2010.

Em 2011 estava esgotada com todo este processo que já virará um tipo de obsessão. Não conseguindo achar uma saída do cãos que havia se instaurado sofro de um surto psicótico, até que um dia, acordo com uma decisão pontual: guardar o fotógrafo e ficar com a câmara.

Em 2013 me mudo para Boston nos Estados Unidos, compro uma câmara e dou início ao meu trabalho autoral enquanto uma artista híbrida (visual, corpo e escrita) e começo a experimentar ações feitas diretamente para a câmara. Gosto de pensar o que faço hoje como ações do corpo para a câmara não o defino como performance ou videoarte e não me interessa enquadrá-lo, deixo-o livre sem nomenclaturas, pois, o que se configura para mim é um processo como procurarei demonstrar no decorrer deste artigo.

\section{O corpo em Perceção: uma visão}

Para falar de perceção acho importante levantar as questões acerca de uma das correntes mais influentes e importante do século XX para a filosofia que é a Fenomenologia e que serviu como um método para vários filósofos pensar e refletir sobre suas filosofias. A fenomenologia abarcou diferentes direcionamentos, mas, se tratando de um movimento filosófico foi com Edmund Husserl que se iniciou. Ele criou uma nova conceção para o termo, que antes, já era utilizado por Kant e Hegel (LIMA, ABM, 2014). Mas, o que me interessa aqui, é convocar a fenomenologia a partir do pensamento propriamente do filosofo Merleau-Ponty que se apropriou e reformulou com maior fidelidade o pensamento de Hussel.

Mas o que seria então a fenomenologia segundo Merleau-Ponty? Para ele, a fenomenologia era a ciência que observava o mundo antes dos conceitos e das ideias já estabelecidas, ou seja, o homem primeiramente observa e percebe para então este processo ser introduzido em seu campo de consciência tornando-se assim um fenómeno. Em seu livro Fenomenologia da Perceção Merleau-Ponty (1945) nos diz que:

\begin{abstract}
A fenomenologia é o estudo das essências (...).mas é também uma filosofia para a qual o mundo já está sempre 'ali', antes da reflexão, como uma presença inalienável, e cujo esforço todo consiste em reencontrar este contato ingênuo com o mundo, para dar-lhe enfim um estatuto filosófico. É a ambição de uma filosofia que seja uma 'ciência exata', mas é também um relato do espaço, do tempo, do mundo 'vividos'. É a tentativa de uma descrição direta de nossa experiência tal como ela é, e sem nenhuma deferência à sua gênese psicológica e às explicações causais que o cientista, o historiador ou o sociólogo dela possam fornecer. (...). (Merleau-Ponty 1999, 1).
\end{abstract}

A fenomenologia segundo as invocações de Ponty, abraça, e também fundamenta, enquanto uma ciência as perceções que aqui convoco. Pois parto da perceção de um tempo vivido onde não se era determinado por conceitos pré-definidos, mas da experiência do primeiro olhar, um olhar com características primária, mesmo carregado de todo o contexto de onde eu vinha, existia, no entanto, um corpo aberto ao por vir. Apesar de Ponty nos dizer que o conhecimento do mundo e suas perceções estejam longe de ser determinada por um psicologismo eu menciono este corpo percetível que abraça o pensamento de Ponty também à uma experiência do devir daquilo que pode torna-se referindo-me há um conceito atualizado pelo filósofo Gilles Deleuze e pelo psicanalista Felix Guatarri.

Para Deleuze devir não significa imitar alguma coisa ou uma pessoa ou mesmo se identificar, devir significa pensar a partir das formas e dos órgãos e do sujeito que se tem para então

(...) extrair partículas, entre as quais instauramos relações de movimento e repouso, de velocidade e lentidão, as mais próximas daquilo que estamos em vias de nos tornarmos, e através das quais nos tornamos. É nesse sentido que o devir é o processo do desejo. (Deleuze, Guattari 1997, 64).

O corpo quando tomado por experiências que perpassam por um percurso de perceção de um corpo que pode tornar-se, e, estando presente dentro de uma esfera de espaço e tempo que não sejam automatizados ou pré conceituados, e ou, cercado por uma sinceridade de movimento, faz com que, se crie uma experiência e tomada de conceção do mundo e das coisas que o cercam muito mais intrigante e reveladora do que ao contrário. Cria-se ali, mesmo, um processo de desejo, que faz com que te instigue a perceber o que não seria experimentado se não tivéssemos uma tomada de consciência de uma perceção própria. 


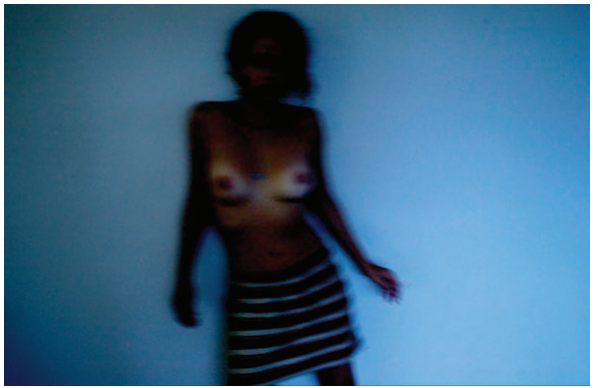

Figura 5 - Cristianne de Sá e X, 2004.

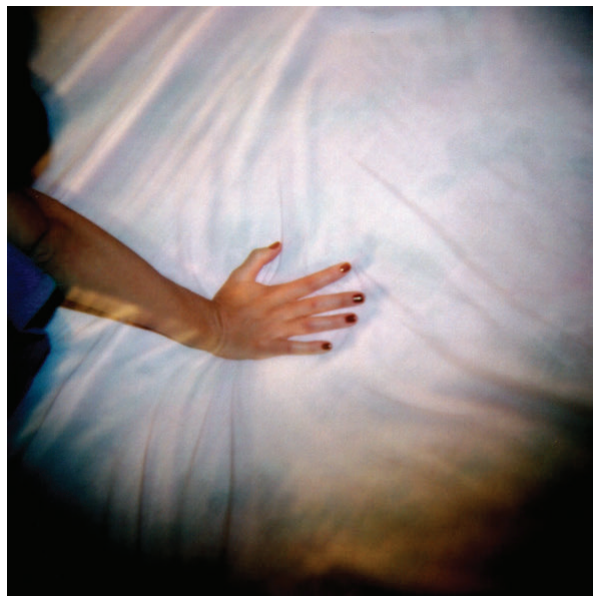

Figura 6 - Cristianne de Sá e X, 2005.

Por isso, o corpo que contextualizo nesta experiência pode ser visto como um corpo-obra ou um corpo-arte ou um corpo-processo em devir, ou como bem percebeu Ponty, não só comunicando as perceções ou sensações, mas, novas possibilidades de ser e estar, novas formas de perceber, conhecer e pensar o mundo e a si mesmo.

Lembro-me que quando a vivência deste encontro se quebrou e rompeu, eu fui acometida da necessidade de escrever sobre este tempo, espaço e perceção como alguém que estivesse reconfigurando o que se tornou, o eu-outro, como um processo de perceção-reflexão que agora era tomado por uma consciência veloz de tudo que se passou, mesmo que muitas destas cartas sejam também dotadas de um corpo agora despedaçado, desconfigurado e ao avesso. Talvez também, fantasiosa, mas ainda assim, completamente integra do processo de desejo.

A cada instante também eu fantasio acerca de coisas, imagino objetos ou pessoas cuja presença aqui não é incompatível com o contexto, e, todavia, eles não se misturam ao mundo, eles estão adiante do mundo, no teatro do imaginário. (Merleau-Ponty 1999, 6).
Foram cartas e mais cartas enviadas para o e-mail de X. O título de uma delas era: eu vou Ihe mandar quantas cartas eu quiser. Ou seja, ele me fotografou o quanto desejou, mesmo eu desejando também estar ali, mas a ação de fotografar-me partia dele, e agora, o desejo e a ação de escrever eram meus, eu não me importaria com nada, eu iria lhe escrever até o limite de não ter mais que guardar somente comigo o pensando acerca daquele tempo. Todo o silêncio que eu me acometi se decorreu agora em um fluxo de palavras. O cuidado em não dar nomes e respostas a nada tomou lugar por um extinto explosivo de vasão de uma perceção, agora tomada por uma consciência, cheia de ideias, perguntas, respostas, dúvidas, raiva e medo. Um corpo sem identidade, ou seja, é essa, então, a tomada de consciência o fenômeno levantado por Ponty.

\section{A relação com a câmara e com o ato de ser fotografada: o despertar}

É importante acentuar que a experiência que se decorre aqui não se concentra na câmara nem somente nos momentos do ato fotográfico, mas enquanto vivências, experiências e na cumplicidade e divergência de ser fotografada e depois também fotografar que existe nestes cotidiano. Enforma e informa situações que foram fotografadas, não pelo sujeito que dominou o disparo fotográfico (o que confere a esta atitude uma ação que enquadra o ato numa moldura de corpo/ação expandida) mas pelo inverso, pelo corpo fotografado, corpo que muitas vezes é considerado objeto, como um receptor passivo e avesso às coisas que nos rodeiam. Sou um corpo que percebe, não sou coisa (Merleau-Ponty 1999).

Com a cisão entre a consciência e o corpo quem adquire o poder de competência é a razão, uma vez que o corpo é apenas um objeto, ainda que de desejo, que transmite informações à razão através dos sentidos - não apenas para o observador, mas, e essencialmente, para ele próprio. $\mathrm{O}$ isolamento parcial do corpo em relação ao mundo exterior - e o que no nosso entender - é o mais importante - para coadjuvar na nossa causa - o corpo objeto. Afinal o que é o corpo? Na conceção cartesiano, ao que parece, mero objeto, pois a conceção do "cogito, ergo sum", ou "sou logo existo", é o que alicerça todo o sistema racionalista cartesiano e abre o subjetivismo moderno. Para Descartes o melhor caminho para se chegar ao conhecimento da verdade é a dúvida que é também o ponto de partida para se chegar a todo o resto. Assim, como qualquer outro corpo, na natureza, somos submetidos às leis mecânicas naturais, o que já traz consigo a consciência de que somos corpóreos. Com este ponto de vista a formar o nosso intento, podemos afirmar que também somos corpo/objeto como qualquer outro. $\mathrm{O}$ que pode ser entendido que o corpo é um objeto - por ser ele no espaço - como também o é uma arvore, uma cama e qualquer coisa que seja corpórea, não obstante, o corpo (próprio) se experiencia e experiencia a realidade que o circunda. O próprio corpo pode ser sujeito (no sentido de se sujeitar, está disposto a alguma coisa ou ação), 
não exclusivamente às leis da física, mas aos seu quereres, vontades e intenções.

Aqui é o corpo fotografado que nos informa sobre o percebido, um corpo do sexo feminino e que aos 23 , era sexualmente limitado, situado num contexto mais genuíno, da minha parte, e um vislumbramento por parte de $\mathrm{X}$, estava instaurado ali, para um fotógrafo que já se percebia também enquanto um artista, um desejo também pelo mito da musa, presença constante na história da $a^{2} e^{4}$. Inclusive, na Grécia arcaica, século VIII a.C. a origem da poesia era vista como sagrada e o impulso da produção desta poesia eram atribuídas às deusas ou musas que eram tidas como sagradas ou revelações divinas - um período em que a divindade não era objeto de discussão, mas fenômeno inegável como a própria luz do dia.

As musas, patronas de toda beleza e toda sabedoria, os poetas são os eleitos das deusas que decidiram, como narra Hesíodo na Teogonia, fazer de homens comuns, e independentemente da vontade destes conhecedores privilegiados do sublime. (Krausz 2007, 16).

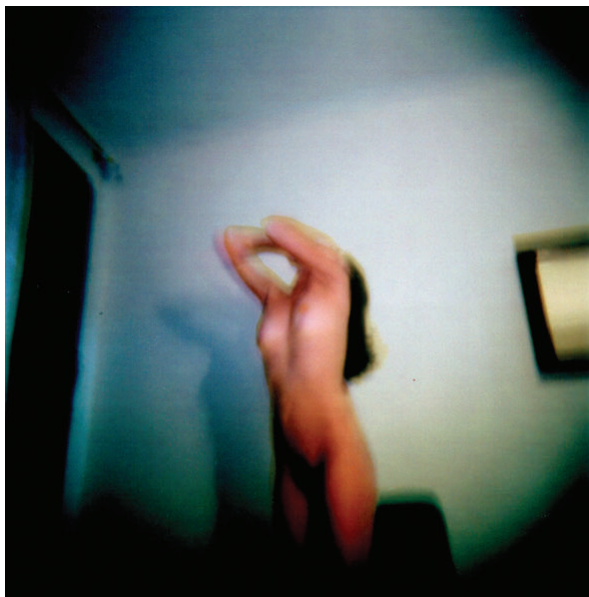

Figura 7 - Cristianne de Sá e X, 2006.

Eu não tinha nenhuma vaidade e pretensão a querer ser uma musa. Nunca usávamos a palavra musa, mas eu já sentia que havia esta relação. Uma relação mítica ou simbólica. Um dia em uma praia, já em 2007, ele me pediu para tirar o chinelo e fincar os pés em um mangue, eu lembro que eu afundei bem meus pés naquela lama preta, ele queria que eu adentrasse mais, eu disse que não e logo depois saí andando à sua frente fazendo marcas de barro com os pés naquele chão de areia fina e branca. Ele me chamou, eu olhei para trás e ele disse-me pela primeira e única: - você sabe que você é minha musa né!? Eu disse: - sei! Me esquivando de qualquer demonstração e revelação exata da nossa relação, mais uma vez eu não queria dar nomes a nada, eu tinha muito receio que ao fazer isso, a experiência e a incógnita se findassem e aquilo que vivíamos, ou seja, a experiência e perceção genuína que existia principalmente da minha parte, se acabasse apesar de acreditar, também, em um caráter genuíno por parte dele comigo. Mesmo que controverso, mas existia.

Já mais para o final destes encontros o meu corpo já estava outro, e ao ser fotografada, o meu corpo agora surgia com movimentos em que já não eram mais recatados e tímidos, eu já insinuava para $X$ um corpo mais decisivo, eu já sabia alguma coisa que eu queria dizer com aquela imagem.

Lembro-me que nesta mesma viagem, no litoral sul da Bahia, paramos o carro em uma estrada e eu saí correndo em direção a vários pes de coqueiros que que se dispunham de uma forma alinhada e simétrica (... eram lindos!). Me aproximei de um, levantei minhas mãos e minha cabeça da forma mais alongada que eu poderia fazer e com o corpo bem erguido pedi para fotografar-me. Eu lembro-me de ter dito que eu tinha me tornado árvore - e a árvore talvez, havia se tornado eu e $X$ o vento - eu nunca vi esta fotografia... mas de acordo com Bergson:

Ora, a vida é uma evolução. Concentramos um período dessa evolução numa vista estável a que damos o nome de forma e, quando a mudança se tornou suficientemente considerável para poder vencer a feliz inércia de nossa percepção, dizemos que o corpo mudou de forma. Mas, na verdade, o corpo muda de forma a todo instante. Ou antes não tem forma, uma vez que a forma é algo imóvel e a realidade é movimento. O que é real é a mudança contínua de forma: a forma não é mais que um instantâneo tomado de uma transição. (Bergson 2005, 327).

O que Bergson (2005) parece querer nos dizer neste trecho de "A evolução Criadora" é que o corpo é dotado de uma constante transformação e que estamos sempre em mutação mesmo que muitas das vezes a inercia e incapacidade de perceção nos impeça de perceber esta transição. Acredito que o mesmo acontece quando Deleuze e Guattari (1997) quando falam em devir, não existe um ser antes e um ser depois, são transações, eu posso tornar-me um corpo desconfigurado em devir, mas não deixo de ter comigo o corpo configurado, onde este, como salienta Bergson, estava cristalizado e acometido por uma inercia ao ponto de achar que ele tinha uma forma. Eu me torno um eu-outro a partir deste movimento e ambiente ao ser fotografada pois é a partir das potências de observar e interromper a inercia que $X$ começa a interferir neste meu corpo cristalizado.

A religião e o catolicismo fizeram parte da minha vida desde criança e mesmo tendo uma abertura em ouvir o outro e sua forma de ver o mundo eu carregava comigo de forma bem rigorosa algumas características conservadoras vindas da forma como fui criada; a família típica cristã brasileira. Durante o período levantado aqui, quando conheci $\mathrm{X}$, aos 23 anos, havia pouco tempo que eu havia decidido não frequentar mais a Igreja Católica.

Através desta relação com a fotografia eu acabei descobrindo que eu tinha um grande trauma, 
uma certa reprimenda física/sexual, causado pelo patriarquismo e conservadorismo impregnado pelos dogmas da religião, que tem a visão do corpo, e consequentemente do sexo, como algo pecaminoso ${ }^{5}$.

Entretanto, esta relação com a câmara além de despertar-me uma realidade escondida, que eu própria escondia de mim mesma e incubada que era o trauma, despertou-me e posicionou-me também para um corpo mais livre e pronto para os palcos do teatro, fez de mim uma atriz cuidadosa com cada gesto expressado, fez-me mais forte, corajosa e imponente. Virou-me também do lado contrário, controverso, desconfiguroume deixou-me mais triste, cética, intensa e sensível à vida. Nunca fiz terapia e não considero o que se passou como uma forma de, mas não podemos negar que em tudo que fazemos que perpassa pela reflexão, experiência e perceção são também como um tipo de dispositivo curativo que alinhavam o estar no mundo, fazendo-nos um ser em constante movimento e no meu caso, lado a lado de um ser também estético.

Susan Sontag (2004) nos diz algo bem delicado em relação ao ato fotográfico e levanta questões como a capacidade que esta ação tem também de ser uma violência.

(...) existe algo de predatório no ato de tirar uma foto. Fotografar pessoas é violá-las, ao vê-las como elas nunca se veem, ao ter delas um conhecimento que elas nunca podem ter; transforma as pessoas em objetos que podem ser simbolicamente possuídos (...). (Sontag 2004, 23).

A minha experiência com $X$ foi reveladora e impulsionadora na criação de um movimento e ato estético próprio e consciente, do confronto entre personagem e autor e de quando eu-personagem, diria, vejo-me completamente incomodada com aquilo que de certa forma estava subjugado a mim, uma passividade diante a autoria e a presença. Um descuido por parte de $\mathrm{X}$, fazendo-me sentir um objeto mesmo, sem direção e destroçado. Por vezes ouvi $X$ dizer que eu teria percentagem de venda daquelas imagens, mas a questão não estava aí. Naquele momento, o que se passava, era maior, não queria para mim um personagem acrítico e muito menos ser personagem. Não se tratava de percentagem, se tratava de um pensamento e que quando olhassem minha imagem, soubessem que eu ou ela não estavam ali somente enquanto uma fotografada ou modelo mas enquanto um corpo presente, autor, e ou, coautor dele próprio, participante de uma experiência e de um processo pontual e decisivo que não tinha mais volta. Originou-se então, um leitmotiv para o meu trabalho autoral, um tipo de estética que sempre reaparece nos meus trabalhos e que é concordante com a minha experiencia e corpo na imagem e que esta sempre ali, como um condutor, uma inquietação ou uma semente originando caminho.

\section{Conclusão}

A minha relação com a câmara e com o ato de ter sido fotografada passou também por um tipo de violência (ou violação?), mesmo eu estando durante esta experiência em profundo estado de desejo e ansiedade preceptiva, mas ela persistiu, e fez com que $X$ repensasse 0 ato de fotografar pessoas, talvez, como uma mudança de fase, e ou, tomada de conciência. Já no final deste processo de ser fotografada, $X$ tornara um artista importante, com trabalhos fortes e de um estudo profundo. Merecido por ele e disso não tenho dúvidas. Entretando, acho importante, atentarmos ao ato fotográfico quando este envolve uma pessoa, à sua simbologia e objetificação. Há aí algo que precisa ser sempre relembrado e repensado. Fotografar o outro é adentrar em seu corpo e isso requer que o fotógrafo ou artista estejam também disponíveis para a complexidade que isso pode vir causar no personagem, modelo ou como quiserem aqui nomear, quando este, entretanto, resolve ser coautor da sua própria imagem.

Quando existe um tipo de relação no ato de ser fotografado que ultrapassa a relação fotógrafofotografado, ou dito de outra forma, autor-modelo, e que ambos são capazes de mutações viscerais e não apenas ações passivas por parte do personagem, eis então um tipo de experiência que pode ser reveladora, para ambos, tendo aí um tipo de enquadramento relevante - autoria partilhada!

É importante também, acentuarmos, que a consciência artística se forma, por diferentes caminhos... e aqui, se faz necessária esta minha afirmação: a experiência aqui relatada se deu por meio das circunstâncias do acaso/acidente, ela se deu através da minha própria perceção (querer, ainda que velado). Acredito que o acaso, o acidente, faça parte desta construção, mas que não elaboramos uma consciência artística vindo somente destas condições. É preciso que estejamos atentos ao que o corpo e sua perceção sejam capazes de nos dar. Quando o acaso nos proporciona um grande encontro que movimenta uma tomada de consciência e atitude podemos afirmar que $\mathrm{o}$ ato criador se complementa.

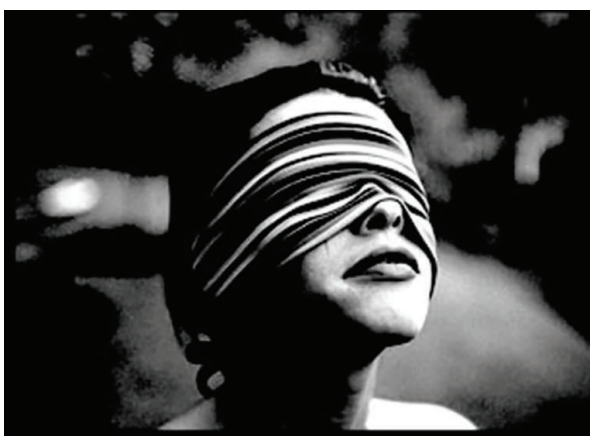

Figura 8 - Cristianne de Sá e X, 2003. 
Em jeito de considerações finais, deixo-vos aqui, com umas das poucas fotografias que ainda tenho comigo desta experiência, as outras, inúmeras delas, estão apenas na minha memória e talvez guardadas com X.

\section{Notas Finais}

${ }^{1}$ Caminha discutindo a ideia de corpo próprio diz: "corpo próprio é o corpo que experimento a mim mesmo, o outro e o mundo. É aquele que afirmo ser meu próprio corpo. Nesse sentido, nem todos os movimentos do corpo humano é regido por leis físicas. Mas como um corpo, que realiza movimentos mecânicos, provocados por causas externas, pode expressar movimentos intencionais e constitui-se sujeito por meio de tais movimentos? Se o nosso corpo é capaz de realizar movimentos que não dependem exclusivamente de uma causa externa, podemos afirmar que ele pode desempenhar movimentos voluntários, que se originam das intenções, dos desejos e das vontades do próprio corpo" CAMINHA, Iraquitan Oliveira. Corpo, Motricidade e Subjetividade em Merleau-Ponty, 2012, p. 39.

2 RESENDE, Fernando. Novo Jornalismo. Coronel Fabriciano, Unileste, 2004. Entrevista concedida a Cristianne Sá.

${ }^{3}$ Por uma questão de preservação de identidade e pelo facto de que aqui me interessa mais o ato do que a pessoa.

${ }^{4}$ Mulher ou tornar-se mulher objeto de desejo - o mito da pintura machista que ainda hoje atravessa a cultura ocidental.

${ }^{5}$ Curioso que a religião não castra apenas a mente...quando tentei iniciar minha vida sexual com alguém que eu amava eu não senti desejo apenas dor... o desejo e o prazer aprendemse, apreendem-se e educam-se!

\section{Referências bibliográficas}

Daolio, Jocimar. 1995. Da cultura do corpo. Campinas, SP: Papi-rus.

Maerleau-Ponty, M. 1999. Fenomenologia da percepção. Tradução Carlos A. R. de Moura. 2. ed. São Paulo: Martins Fontes.

Dubois, Philippe. 1999. O Ato Fotográfico. São Paulo: Papirus.

Lima ABM., org. 2014. Ensaios sobre fenomenologia: Husserl, Heidegger e Merleau-Ponty [online]. Ilhéus, BA: Editus.

Deleuze, Gilles; Guattari, Felix. 1997. Mil Platôs: capitalismo e esquizofrenia. Trad. Suely Rolnik. Vol. 4. Rio de Janeiro: Editora 34.

Krausz, Luis S. 2007. As Musas: poesia e divindade na Grécia Arcaica. São Paulo: EDUSP.

Bergson, Henri.2005. A evolução criadora. São Paulo: Martins Fontes.

Sontag, Susan. 2004. Sobre fotografia; tradução Rubens Figueredo. São Paulo: Companhia das Letras.

Este trabalho é financiado por fundos nacionais através da FCT - Fundação para a Ciência e a Tecnologia, I.P., no âmbito do projeto «UID/DES/4057/2019». 